\title{
Sewer Ventilation: Factors Affecting Airflow and Modeling Approaches
}

\author{
Scott A. Lowe \\ Manhattan College, Riverdale, New York.
}

\begin{abstract}
Sewer ventilation modeling and analysis is typically performed as part of an odour study. Sewer system hydraulic models can be expected to produce reasonably accurate, dynamic results across an entire system. Sewer ventilation models have much less capability. This is not due to technological limitations but rather the nature of the problem. This paper describes the major factors that affect the flow of air in sewer systems, and reviews the existing ventilation models. The paper also discusses the challenges facing future iterations of ventilation models.
\end{abstract}

\section{Introduction}

The field of sewer ventilation modeling is a niche area within the general sewer modeling field. Sewer ventilation models are generally used as part of an analysis to determine odour emissions from a proposed or existing sewer system. Computed ventilation rates are combined with measured or estimated concentrations of odour producing substances to generate mass emission rates. The most common substance analysed is hydrogen sulphide, although certain volatile organic compounds (VOCs) are also known to have odour potential (Dincer and Muezzinoglu 2008).

Ideally sewer ventilation models can predict places in a sewer system where the venting of sewer gases is likely to occur. Additionally they should be able to estimate the air flow rates so that mass flow rates exiting the system can be calculated. These can then be used as input for air quality dispersion models to determine if there will be odour problems. Air flow rates are also required for the design of air treatment facilities (ATF) to control odours.

Another use for ventilation models is to calculate corrosion potential in systems. The same components (i.e. sewer ventilation rates and hydrogen sulphide concentrations) are needed.

This paper focuses on the factors that influence the flow of air in sewer systems, drawing on the current understanding of the processes involved. This includes both well known phenomena, such as air-water drag in sewer pipes, through to buoyancy driven air flow in empty combined sewer overflow (CSO) tunnels -a niche topic on which no published journal papers yet exist. This paper does not address the concentration component of the problem. Finally the current modeling approaches are reviewed, with a discussion on how the present models are performing.

\section{Factors Affecting Airflow in Sewer Sys- tems}

\subsection{Water Drag}

The most important factor in determining sewer airflow is typically the drag between the water surface and the air in the headspace, as shown in Figure 1. It is found that due to this effect, airflow in sewers is always in the direction of the water flow (WERF 2009) unless mechanically forced otherwise. The air velocity is typically less than the water velocity, with average air velocities usually in the range of $5 \%$ to $30 \%$ of average water velocities (Pescod and Price 1982).

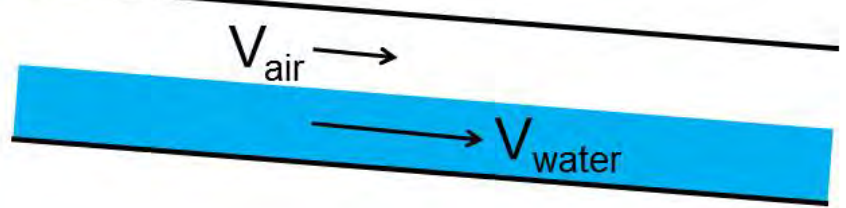

Figure 1 Drag induced airflow in a sewer.

When airflow at a downstream section is less than at an upstream section, the airflow difference will vent at the nearest manhole. This will occur, for example, when the slope decreases, so causing the water depth to increase and the water velocity to decrease. This will cause not only a decrease in the air velocity, but also a decrease in the headspace. The combination of these will cause a significant drop in the air flow rate. This is shown in Figure 2 .

Lowe, S. 2016. "Sewer Ventilation: Factors Affecting Airflow and Modeling Approaches." Journal of Water Management Modeling C395. doi: 10.14796/JWMM.C395.

(c) CHI 2016 www.chijournal.org ISSN: 2292-6062 


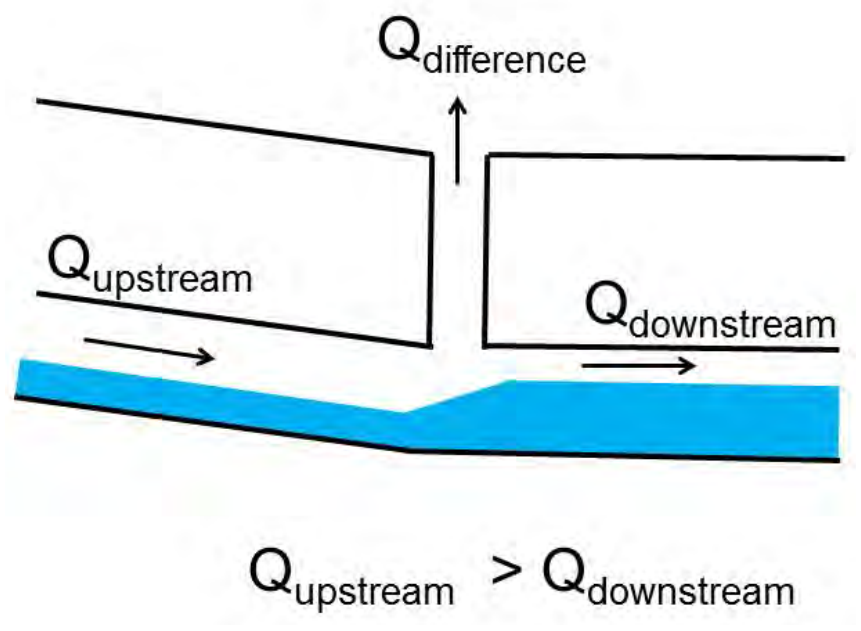

Figure 2 Sewer venting caused by airflow differences.

The converse of this situation is shown in Figure 3, causing air to be drawn into the system.

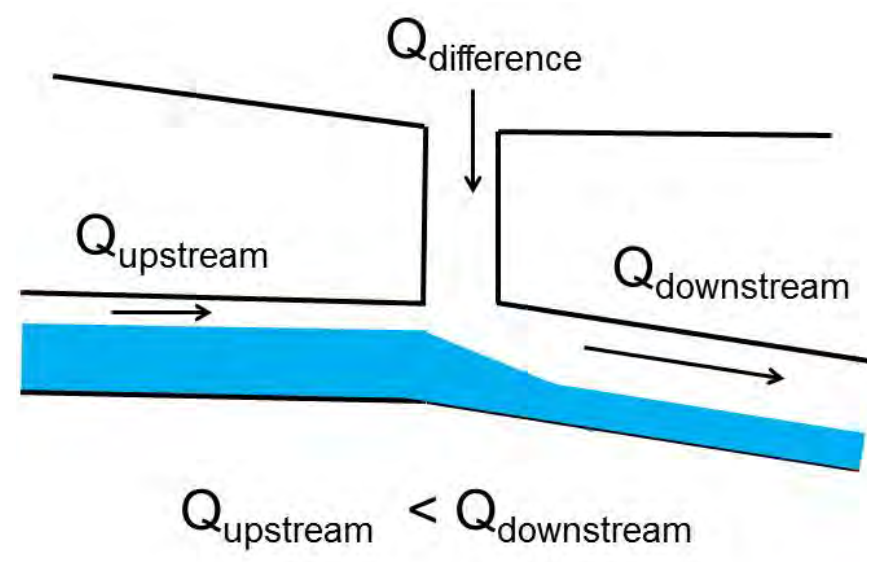

Figure 3 Air drawn into sewer due to airflow differences.

Ideally it would be possible to reasonably predict the air velocity based on water velocity. This would allow the airflow rates to be calculated. However results of field studies have consistently shown that there is more variation in airflow rates, and thus air velocity, than can be explained by just water velocity alone (Madsen et al. 2006).

\subsection{Air Pressure}

This leads to the second major factor: the air pressure distribution in the system. Air, like all fluids, will flow from high pressure to low pressure. Unlike water, air is a compressible fluid and compressibility effects can be important. If the air pressure in a system could be accurately computed then the resulting air flow could also be calculated with reasonable accuracy.

If the system were closed then this might be possible. In a real sewer system there are thousands of openings to the ambient atmosphere such as manholes and drop shafts. These basically present poorly defined boundary conditions in terms of modeling. Experimental studies have shown that there are poor correlations between manhole and pipe pressures, and measured parameters would be thought to influence pressure. These include wind speed, air temperature, sewer headspace temperature, atmospheric humidity, sewer headspace humidity, and atmospheric pressure (e.g. Parker and Ryan 2001).

The air pressure differences that affect airflow rates are also small. Local atmospheric motion, for example, is typically driven by pressure differences on the order of 4 mbar. Given that the ambient pressure is about 1013 mbar, the driving difference is about $0.4 \%$. A pressure of $4 \mathrm{mbar}$ is the equivalent of $\sim 40 \mathrm{~mm}$ of water. Pressure differentials from manhole to manhole measured by WERF (2009) and Pescod and Price (1982) found differences on the order of $0.02 \mathrm{mbar}$, the equivalent of $0.2 \mathrm{~mm}$ of water.

\subsection{Drop Structures}

Sewer systems also contain various hydraulic structures besides pipes and manholes. These structures affect the air flow. Drop structures, for example, are common and have complicated water and airflow characteristics (Zhao et al. 2006).

There are two main types of drop shafts: vortex and plunge. Vortex shafts cause the flow to spiral down and cling to the walls of the shaft, thereby minimizing air entrainment and hydraulic shock effects. Plunge shafts allow the water to freefall. Some drop shafts have vents and deaeration chambers to reduce the amount of air entering the downstream pipes.

Figure 4 shows one scenario where air is drawn into the system. In this case air is also entrained in the flow. The entrained air will usually deaerate further downstream.

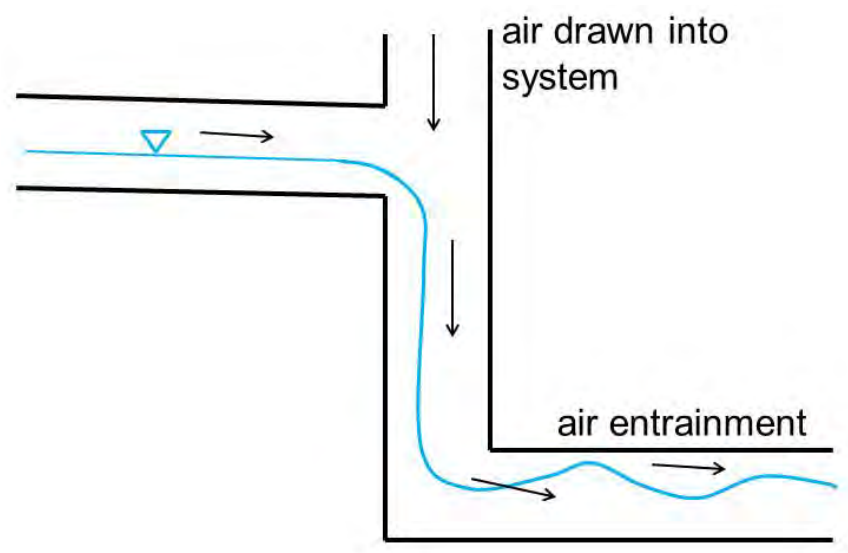

Figure 4 Air drawn into a drop structure.

Another drop structure scenario is shown in Figure 5. In this case the water surface forms a temporary air flow block that causes the upstream airflow to vent at the structure. Drop structures where perpetual venting occurs are often the point of odour problems for sewer systems (Corsi and Quigley 1996). 


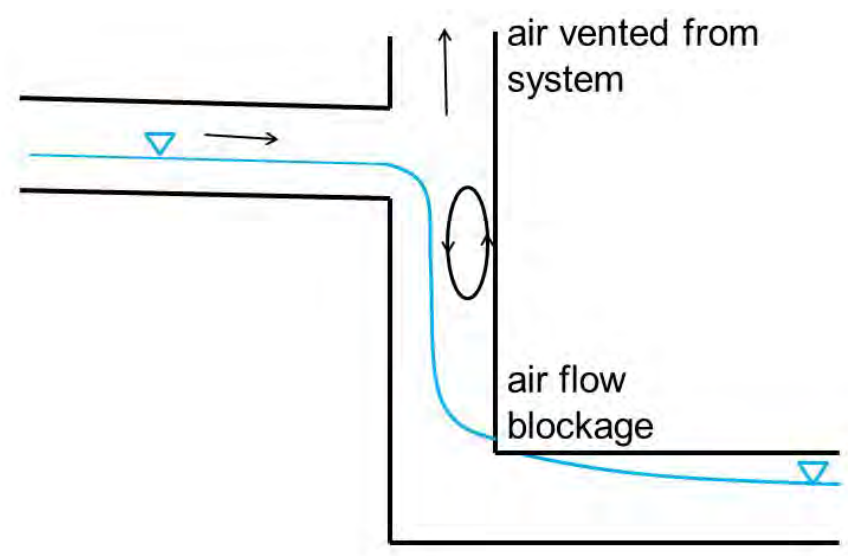

Figure 5 Air vented at a drop structure.

\subsection{Buoyancy Effects}

The air in sewer systems is often less dense than the ambient air (Pescod and Price 1981). This is due to two factors: humidity and temperature. Although counterintuitive, more humid air is less dense. This is because water vapour, with a molecular weight of $18 \mathrm{~g} / \mathrm{mol}$, is less dense than both nitrogen $\left(\mathrm{N}_{2^{\prime}} 28 \mathrm{~g} / \mathrm{mol}\right)$ and oxygen $\left(\mathrm{O}_{2}, 32 \mathrm{~g} / \mathrm{mol}\right)$. Not surprisingly the air in sewers tends to be more humid than the ambient air. In winter the air in sewers also tends to be warmer, and hence lighter, than the ambient air. So a CSO tunnel, for example, that is empty will see more dense air enter and displace the lighter air in the tunnel, along with odours (Joyce et al. 2000). This is an example of buoyancy-driven circulation, also called the stack, or chimney, effect. This is shown in Figure 6.

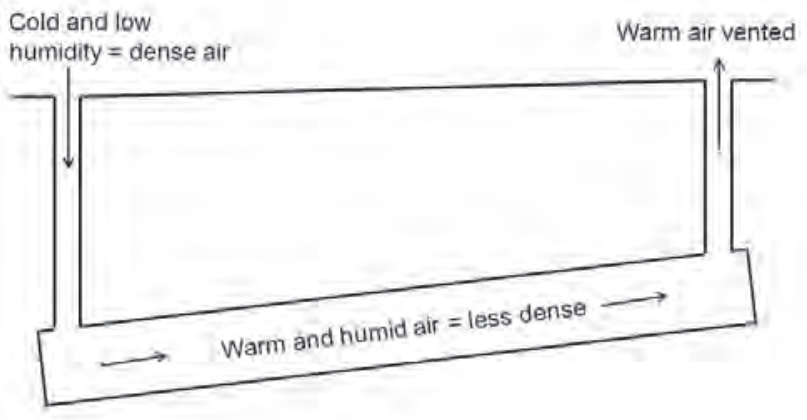

Figure 6 Buoyancy driven venting of an empty CSO tunnel.

\subsection{CSO Storage Tunnels}

CSO storage tunnels (or any other sewer tunnel designed to act as temporary storage) are also unique in that they are designed to fill, as shown in Figure 7. As the tunnel fills the headspace is eliminated, effectively blocking the downstream flow of air. Additionally the volume of water filling the tunnel will displace approximately the same volume of air. This air will move upstream to the nearest drop shaft and join the upstream air flowing out of the drop shaft. This creates huge airflow rates during CSO events.

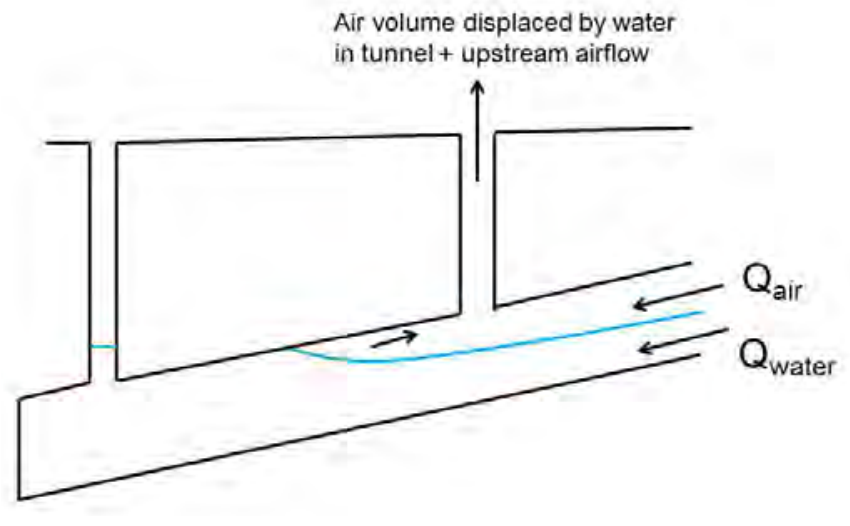

Figure 7 A filling CSO tunnel expels air.

\subsection{Siphons}

Siphons produce a complete barrier to airflow as the siphon pipe is completely full. This means that all airflow must vent at the upstream end of the siphon, as shown in Figure 8. This creates the potential for an odour hot spot. One solution sometimes employed is to create an air jumper by using a small pipe connecting the upstream and downstream headspaces (Deering et al. 2006). This allows the air to keep flowing downstream.

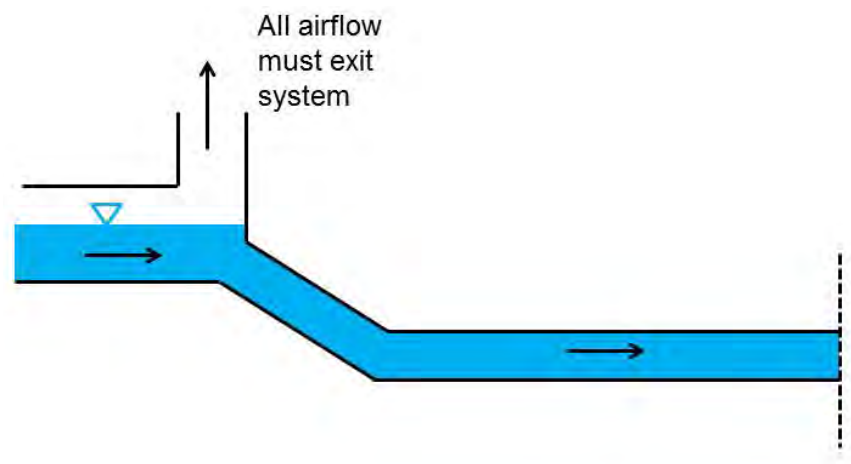

Figure 8 Air venting at the upstream end of a siphon.

\section{Modeling Approaches}

\subsection{Existing Models}

In general there are three main approaches to modeling sewer ventilation. Ranked in terms of popularity they are:

1. Empirical;

2. Computational; and

3. Thermodynamic.

Empirical models tend to correlate measurable, or readily calculable, hydraulic parameters with air velocity. There are many versions of empirical relationships that have been used over the years. Arguably the most popular of these is based on an experimental study by Pescod and Price (1982): 


$$
V_{\text {air }}=0.397\left(W V_{w} / P_{\text {air }}\right)^{0.7234}
$$

where:

$V_{\text {air }}=$ average headspace velocity $(\mathrm{m} / \mathrm{s})$,

$W=$ water surface width $(\mathrm{m})$,

$V_{w}=$ water velocity $(\mathrm{m} / \mathrm{s})$, and

$P_{\text {air }}=$ headspace pipe perimeter $(\mathrm{m})$.

Computational models are generally finite element based computational fluid dynamics (CFD) models (e.g. Edwini-Bonsu and Steffler 2004; Wang et al. 2011). These models either compute the air and water flow, or import the hydraulics and limit the numerical model to the air regime.

Thermodynamic based models (e.g. Olson et al. 1997) are the least common. These models tend to work best for calculating buoyancy driven airflow.

A Water Environment Research Foundation (WERF) study (WERF 2009) tested one of each type of model. They found that all the models tested were fairly inaccurate, and tended to over-predict most of the time. The models were most inaccurate at low airflow rates-with order of magnitude over-predictions. At higher flow rates the models performed better, in some cases almost matching the measured flows, and generally being within a factor of 2 to 3 .

It should be noted that from a design point of view the fact that models tend to overestimate air flows is not necessarily a bad outcome. The fact that models perform well at high airflow rates is also a positive result.

All of the approaches discussed above are steady state. Given the difficulty in getting steady state models to produce reasonable results, the development of dynamic models is not a priority at this point. The exception is the calculation of air flows due to the filling of tunnels. In this case dynamic hydraulic modeling results are used directly.

\subsection{Future Models}

It is necessary to realize that air related problems are inherently difficult to analyse. In air quality dispersion modeling, for example, any result within a factor of 2 to 4 of a measured concentration is probably considered good (Miller and Hively 1987). There will always be the inclination to think that sewer air modeling should be able to be done to the level of sewer hydraulic modeling, but this will likely never be the case. However there are also many cases of where modeling has been used to successfully identify problem areas in systems, and result in design solutions (e.g. Pistilli and Joyce 2012; Hentz et al. 2013; WERF 2007).

In the future it will be desirable to have ventilation models produce results similar to hydraulic models. These would be models that will generate air pressures, velocities and flows, dynamically, across an entire system. The barrier to this happening is not technological; it is more the nature of the problem.

Odour problems in sewer systems span a large range of timeframes from short term - typically related to rain events-to persistent. Persistent odours can come from buoyancy effects, or occur at points in the system where air is continually vented, for the reasons discussed in Section 2.

Dynamic air models would enable the air flow calculation to generate results in similar detail to the hydraulic calculations. This would be first step in providing time variable odour predictions from which appropriate mitigation strategies could be developed. For example, a location that is known to produce odours only for short durations during the middle of heavy rain events may need no mitigation, as the potential for odour receptors (people) is low.

The processes by which air moves within a pipe system are reasonably well understood. However what happens within the system is also affected greatly by boundary conditions, pressure variations from manhole to manhole being the most important. At present the reasons for these variations do not correlate well with parameters that would logically seem important, like wind speed or ambient air pressure and suchlike. Even if strong correlations could be found it is unlikely that hyper-local meteorological data (i.e. manhole to manhole) will be available.

\section{Summary}

This paper summarizes the factors that influence the flow of air in sewer systems. This is one part of analysing sewer odour emissions. The second piece of the puzzle is determining the concentrations of odour producing substances, typically hydrogen sulphide and certain VOCs.

The main factors affecting the air flow in sewers are summarized as:

1. Water drag;

2. Air flow differences in pipe sections causing excess air to be vented;

3. Air flow differences in pipe sections causing air to be drawn into the system;

4. Pressure variations across the system;

5. Drop structures;

6. Buoyancy effects;

7. CSO tunnel filling; and

8. Siphons.

Presently sewer ventilation models fall into three categories:

1. Empirical;

2. Computational; and

3. Thermodynamic.

In general the models have difficulty in accurately predicting air flow rates, especially low flow rates. Models have proven useful for determining potential problem areas in systems.

The barriers to improved models are not technological but rather the inability to predict the boundary conditions which can greatly influence the system. These mainly concern the pressure variations that exist from manhole to manhole. 


\section{References}

Corsi, R. L. and C. J. Quigley. 1996. "VOC Emissions from Sewer Junction Boxes and Drop Structures: Estimation Methods and Experimental Results." Journal of the Air \& Waste Management Association 46 (3): 224-33.

Deering, S., S. Jepsen, A. Acevedo and M. Taylor. 2006. "Sewer Siphon Assessment and Air Jumper Design." Proceedings of the Water Environment Federation Annual Conference, Dallas, TX, October 21-25.

Dincer, F. and A. Muezzinoglu. 2008. “Odor Causing Volatile Organic Compounds in Wastewater Treatment Plant Units and Sludge Management Areas." Journal of Environmental Science and Health, Part A, 43 (13): 1569-74.

Edwini-Bonsu, S. and P. M. Steffler. 2004. "Air Flow in Sanitary Sewer Conduits due to Wastewater Drag: A Computational Fluid Dynamics Approach." Journal of Environmental Engineering Science 3 (5): 331-42.

Hentz, L. H., S. Eftekharzadeh and R. Atoulikian. 2013. “Ventilation and Odor Control for Sewers \& Tunnels." Ohio WEA Annual Conference, Mason, Ohio, June 18-20.

Joyce, J., H. W. Sorensen and M. M. Smith. 2000. "Large Diameter Sewer and Tunnel Ventilation Characteristics and Odor Control: Recent Developments and Case Histories." Proceedings of the Water Environment Federation Annual Conference, Anaheim, CA, October 14-18.

Madsen, H. I., T. Hvitved-Jacobsen and J. Vollertsen. 2006. “Gas Phase Transport in Gravity Sewers: A Methodology for Determination of Horizontal Gas Transport and Ventilation." Water Environment Research 78 (11): 2203-9.

Miller, C. W. and L. M. Hively. 1987. "A Review of Validation Studies for the Gaussian Plume Atmospheric Dispersion Model." Journal of Nuclear Safety 28 (4): 522-31.
Olson, D. A., S. Rajagopalan and R. L. Corsi. 1997. “Ventilation of Sewers: The Role of Thermal Gradients." Advanced Environmental Research 1(3): 312-22.

Parker, W. J. and H. Ryan. 2001. "A Tracer Study of Headspace Ventilation in a Collector Sewer." Journal of the Air \& Waste Management Association 51 (4): 582-92.

Pescod, M. B. and A. C. Price. 1981. "Fundamentals of Sewer Ventilation as Applied to the Tyneside Sewerage Scheme." Water Pollution Control 90 (1): 17-33.

Pescod, M. B. and A. C. Price. 1982. "Major Factors in Sewer Ventilation." Journal of the Water Pollution Control Federation 54 (4): 385-97.

Pistilli, J. P and J. Joyce. 2012. "Ventilation, Odor and Corrosion Control for Large Diameter Collection Systems." Michigan WEA Annual Collections Seminar, Bath, MI, September 6.

Wang, Y. C., N. Nobi, T. Nguyen and L. Vorreiter. 2011. "A Dynamic Ventilation Model for Gravity Sewer Networks." Water Science \& Technology 65 (1): 60-8.

Water Environment Research Foundation (WERF). 2007. "Minimization of Odors and Corrosion in Collection Systems." Alexandria, VA: Water Environment Research Foundation. Report No. 04-CTS-1.

Water Environment Research Foundation (WERF). 2009. “Collection System Ventilation Research Report." Alexandria, VA: Water Environment Research Foundation. Report No. 04-CTS-1A.

Zhao C. H., D. Z. Zhu, S. K. Sun and Z. P. Liu. 2006. “Experimental Study of Flow in a Vortex Drop Shaft." Journal of Hydraulic Engineering 132 (1): 61-8. 